\title{
Implementasi Natural Language Processing Dalam Pembuatan Chatbot Pada Program Information Technology Universitas Surabaya
}

\author{
Vincentius Riandaru Prasetyo ${ }^{1 *}$, Njoto Benarkah ${ }^{2}$, Vioni Jannet Chrisintha ${ }^{3}$ \\ 1,2,3Program Studi Teknik Informatika, Universitas Surabaya, Surabaya, Jawa Timur \\ Email: ${ }^{1 *}$ vincent@staff.ubaya.ac.id, ${ }^{2}$ benarkah@staff.ubaya.ac.id, ${ }^{3}$ s160416034@ student.ubaya.ac.id
}

(Naskah masuk: 31 Mei 2021, direvisi: 15 Jun 2021, diterima: 17 Jun 2021)

\begin{abstract}
Abstrak
Program Information Technology di Jurusan Teknik Informatika, Universitas Surabaya, merupakan salah satu program yang menggunakan bahasa Inggris sebagai pengantar pada saat perkuliahan berlangsung. Akan tetapi, kurangnya informasi mengenai Program Information Technology menyebabkan kurangnya minat calon mahasiswa terhadap program tersebut. Oleh karena itu, penelitian ini bertujuan untuk membuat sebuah aplikasi chatbot yang dapat membantu user untuk memperoleh informasiinformasi terkait dengan Program Information Technology pada Jurusan Teknik Informatika, Universitas Surabaya. Chatbot yang dibangun hanya akan memproses pertanyaan dengan bahasa Inggris saja. Chatbot yang dibuat pada penelitian ini menggunakan pendekatan Natural Language Processing (NLP) untuk memproses pertanyaan yang disampaikan user dan untuk mendapatkan kata kunci dari informasi yang diinginkan user. Sistem akan melakukan pencarian informasi pada kamus informasi yang ada. Apabila informasi tidak ditemukan, maka sistem akan melakukan proses crawling untuk memperoleh informasi yang dibutuhkan user. Pada penelitian ini, validasi sistem dilakukan dengan dua metode yaitu cross validation dan user validation. Berdasarkan validasi dengan metode cross validation didapatkan akurasi sebesar 83,33\%. User validation dilakukan dengan cara meminta 10 user untuk melakukan uji coba sistem dan didapatkan akurasi sebesar $76 \%$.
\end{abstract}

Kata Kunci:Chatbot, Natural Language Processing, Crawling.

\section{Implementation of Natural Language Processing in Creating Chatbots at Information Technology Program, University of Surabaya}

\begin{abstract}
The Information Technology Program at the Department of Informatics Engineering, University of Surabaya, is one of the programs that uses English as a medium during lectures. However, the lack of information about the Information Technology Program causes a lack of interest among prospective students. Therefore, this study aims to create a chatbot application that can help users to obtain information related to the Information Technology Program at the Department of Informatics, University of Surabaya. The chatbot that is built will only process questions in English only. The chatbot made in this study uses a natural language processing (NLP) approach to process user-submitted questions and to get keywords from the information that the user wants to know about. The system will search for information in the existing information dictionary. If the information is not found, the system will perform a crawling process to obtain the information needed by the user. In this study, system validation was carried out by two methods, namely cross validation and user validation. Based on the validation with the cross validation method, the accuracy is $83.33 \%$. User validation is done by asking 10 users to test the system and get an accuracy of $76 \%$.
\end{abstract}

Keywords: Chatbot, Natural Language Processing, Crawling. 


\section{PENDAHULUAN}

Sejalan dengan perkembangan zaman, teknologi telah mengalami berbagai perkembangan pesat. Salah satunya adalah informasi dapat diperoleh dengan lebih mudah. Kecerdasan buatan merupakan salah satu bentuk teknologi yang mengalami perkembangan sangat pesat di era modern ini. Kecerdasan buatan memungkinkan mesin berpikir dan membuat keputusan sendiri, salah satunya adalah teknologi chatbot. Chatbot atau percakapan dengan robot adalah aplikasi kecerdasan buatan yang dapat mensimulasikan percakapan cerdas antar manusia berdasarkan pengetahuan yang diberikan. Chatbot adalah agen cerdas yang dapat meniru kemampuan manusia untuk berkomunikasi melalui pesan teks [1]. Keberadaan chatbot telah banyak digunakan di perusahaan seperti pada bank untuk membantu menjawab pertanyaan tentang informasi terkait perbankan dan keluhan pelanggan.

Chatbot pada penelitian ini dirancang untuk membantu dalam menjawab pertanyaan yang terkait dengan Program Information Technology, Jurusan Teknik Informatika, Universitas Surabaya. Informasi terkini tentang Program Information Technology hanya dapat diakses di halaman http://teknik.ubaya.ac.id/id/program/information-technologyinternational-dual-degree.html, akan tetapi informasi yang diberikan pada halaman ini masih sangat terbatas. Keterbatasan informasi pada halaman tersebut mengakibatkan kurangnya minat dari calon mahasiswa untuk mendaftar pada Program Information Technology, Universitas Surabaya. Keterbatasan informasi tersebut sebenarnya dapat diatasi dengan bertanya langsung ke Direktorat Marketing and Public Relations (MPR) yang dimiliki Universitas Surabaya melalui telepon, email, ataupun livechatting. Akan tetapi, keterbatasan staf yang ada di MPR menyebabkan masalah baru yaitu human delay, apabila banyak calon pendaftar ingin bertanya dalam waktu yang bersamaan. Selain itu, adanya office hour mengakibatkan calon pendaftar tidak memiliki keleluasaan waktu dalam bertanya. Oleh karena itu, chatbot dipilih karena dapat menggantikan peran manusia untuk memberikan jawaban dengan cepat kepada pengguna tanpa harus harus membaca skimming atau scanning pada sumber data informasi. Pada penelitian ini, chatbot dibangun dengan menggunakan pendekatan Natural Language Processing.

Natural Language Processing atau sering disingkat NLP adalah salah satu bidang ilmu komputer, kecerdasan buatan dan bahasa (linguistik) yang berkaitan dengan interaksi antara komputer dengan bahasa alami manusia. Bahasa alami adalah bahasa yang dapat dipahami manusia. Pada prinsipnya, bahasa alami adalah suatu bentuk informasi yang akan disampaikan dari satu pengguna ke pengguna lainnya. Bahasa alami dapat direpresentasikan dalam bentuk suara atau teks [2].

Penelitian yang berkaitan dengan perancangan aplikasi chatbot sudah pernah dilakukan sebelumnya. Suryani dan Amalia [3] pada penelitiannya membangun aplikasi chatbot yang bertujuan untuk memberikan informasi tentang objek wisata yang ada di Jawa Timur. Pada penelitian tersebut, chatbot dibangun menggunakan konsep Artificial Intelligence Markup Language (AIML). AIML adalah salah satu turunan dari XML (Extensible Markup Language) di mana terdapat kumpulan pola dan respon yang dapat digunakan untuk pencarian jawaban yang diinginkan pengguna chatbot. Berbeda dengan penelitian sebelumnya, Benedictus, et.al. [4] mengembangkan chatbot yang berfungsi sebagai helpdesk untuk melayani tanya-jawab seputar Sistem Informasi Terpadu yang dimiliki oleh Universitas Sam Ratulangi. Chatbot yang dikembangkan pada penelitian tersebut menggunakan algoritma bigram untuk mencocokkan pola kalimat tanya yang diberikan oleh pengguna. Algoritma ini akan membagi suatu kalimat secara berpasang-pasangan. Metode forward chaining juga digunakan pada penelitian tersebut untuk melakukan penalaran terhadap kondisi-kondisi tertentu pada sebuah pertanyaan, sehingga sistem dapat menentukan jawaban yang sesuai. Penggunaan metode forward channing juga digunakan oleh Dwi R, et.al. [5] pada penelitiannya tentang pengembangan aplikasi chatbot yang terintegrasi dengan web CMS pada UKM MINSU. Chatbot yang dibangun pada penelitian tersebut bertujuan untuk menyelesaikan permasalahan pada pelayanan customer service UKM MINSU yaitu kurangnya respon cepat customer service karena harus melayani banyak pelanggan, sehingga dapat menyebabkan hilangnya pelanggan tetap dan berpengaruh terhadap omset penjualan.

Penelitian lainnya yang masih berhubungan dengan chatbot juga dilakukan oleh Amalia dan Wibowo [6] untuk peningkatan performa bisnis. Pengembangan chatbot dilakukan dengan memanfaatkan Chatfuel sebagai bot builder karena memiliki response time yang cepat dalam menjawab pertanyaan dari banyak pengguna sekaligus. Selain itu, penelitian tersebut juga menggunakan Facebook Messanger sebagai platform chatting di mana chatbot akan diintegrasikan ke dalamnya. Berbeda dengan penelitian sebelumnya, Yuniar dan Purnomo [7] membangun sebuah chatbot dengan nama ALITTA yang bertugas sebagai asisten virtual dan pusat informasi pada aplikasi BALITTAS. Dalam membangun chatbot ALITTA, Yuniar dan Purnomo memanfaatkan platform API.AI yang menyediakan layanan NLP dan NLU (Natural Language Understanding). NLU merupakan turunan ilmu dari NLP di mana fungsinya adalah untuk melakukan analisis semantik, sehingga makna dari suatu kalimat dapat dipahami oleh aplikai chatbot.

\section{METODOLOGI PENELITIAN}

\section{A. Chatbot}

Chatbot adalah sebuah aplikasi yang memungkinkan percakapan antara mesin dengan manusia menggunakan bahasa alami manusia. Chatbot sering digambarkan sebagai salah satu cara untuk mensimulasikan interaksi antara mesin dengan manusia. Untuk memahami bahasa alami manusia, chatbot menggunakan pendekatan NLP untuk mempelajari dan memproses setiap kata yang diucapkan oleh manusia berupa pesan teks [8].

Cara chatbot bekerja dimulai dengan menerima input dari pengguna berupa pesan teks. Sistem kemudian menggunakan NLP untuk memproses input untuk menganalisis, mengidentifikasi, dan menafsirkan makna yang dimaksud oleh 
pengguna. Sistem akan memverifikasi input makna dan kondisi dari percakapan yang sedang berlangsung. Setelah sistem memahami artinya, sistem akan mencari data yang dianggap sesuai, kemudian respon berupa jawaban yang ditampilkan kepada pengguna berdasarkan struktur dan bahasa manusia.

\section{B. Natural Language Processing}

Natural Language Processing (NLP) adalah kombinasi dari ilmu komputer dan bidang kecerdasan buatan yang terkait dengan linguistik. NLP berkaitan dengan bagaimana mesin memahami bahasa manusia untuk saling berinteraksi. Dengan adanya NLP, komputer dapat belajar dan memahami bahasa manusia, sehingga komputer dapat berkomunikasi dengan manusia. Bahasa manusia adalah hal yang unik karena dibuat khusus untuk menyampaikan suatu makna. Untuk membuat komputer dapat mengerti bahasa manusia adalah tugas yang sulit, karena bahasa manusia memiliki struktur yang kompleks. Selain itu, setiap bahasa memiliki keunikannya sendiri dan mungkin memiliki makna ganda [9]. Sebagai contoh dapat dilihat dari kalimat berikut, "Look at the dog with one eye", di mana kalimat tersebut dapat memiliki arti "melihat anjing dengan satu mata" atau "melihat anjing yang mempunyai mata satu".

Dua teknik utama untuk memahami NLP adalah syntactic analysis (analisis sintaksis) dan semantic analysis (analisis semantik). Kedua teknik digunakan untuk memverifikasi struktur bahasa. Analisis sintaksis mengacu pada tata bahasa, sedangkan analisis semantik merujuk pada penafsiran suatu kalimat.

Syntactic analysis (analisis sintaksis) adalah teknik pengaturan pada suatu kalimat sehingga kalimat memiliki tata bahasa yang benar. Analisis sintaksis melibatkan penentuan stuktur kalimat seperti subjek, predikat, kata benda, kata kerja, kata ganti, dan sebagainya. Sistem akan dapat membaca input kalimat, yang akan dipecah menjadi kata-kata, dan pada akhirnya menghasilkan deskripsi yang terstruktur. Teknik ini dapat digunakan untuk menyederhanakan kalimat untuk memudahkan pencarian informasi. Selain itu, penggunaan analisis sintaksis juga dapat membantu mendeteksi keberadaan kata atau kalimat baru atau tidak biasa [10].

Sebuah kalimat dapat disebut sebagai kalimat, apabila paling tidak terdiri dari subjek dan predikat, sebagai contoh kalimat "Andi eat". Dengan menggunakan teknik analisis sintaksis, komputer dapat membedakan mana yang termasuk subjek ("Andi") dan predikat ("eat"). Kalimat yang terbentuk mungkin saja tidak memiliki makna apapun, karena analisis sintaksis hanya memastikan bahwa struktur dari sebuah kalimat sudah benar.

Analisis semantik adalah teknik yang digunakan untuk memahami makna dan interpretasi dari struktur bahasa. Seseorang bisa memahami perkataan orang lain berdasarkan intuisi dan pengetahuan dari bahasa itu sendiri. Komputer tidak memiliki intuisi dan pengetahuan semacam ini, sehingga mereka membutuhkan metode lain, yaitu semantik. Semantik adalah proses penting karena output semantik yang diharapkan adalah makna yang terkandung pada sebuah input [10]. Analisis semantik memproses teks untuk mengidentifikasi dan memahami topik yang dimaksud. Semantik juga mempelajari hubungan antara berbagai konsep dalam teks. Sebagai contoh, apabila sebuah teks terdapat kata"money" dan "accounting", maka topik yang sedang dibahasberkaitan dengan "economy".

\section{Keyword Extraction}

Keyword extraction adalah teknik dalam NLP yang menganalisis teks dengan menggunakan keyword atau kata kunci yang terkandung dalam teks tersebut. Dengan menggunakan metode ini dapat membantu meringkas teks dan mengidentifikasi subjek teks. Proses yang dilakukan dalam keyword extraction adalah tokenisasi kata, penghapusan stopword, dan analisis. Tokenisasi adalah teknik pemotongan kalimat menjadi kata-kata. Penghapusan stopword adalah teknik untuk menghilangkan kata umum yang terkandung dalam kalimat, seperti "and", "or", "the", dan sebagainya. Tanda baca dan angka juga merupakan bagian dari stopword. Analisis dilakukan dalam bentuk Part-Of-Speech (POS) tagging, di mana setiap kata diberikan label atau tanda sesuai dengan jenis kata, seperti kata kerja, kata benda, kata ganti, dan sebagainya. Pengambilan kata penting hanya menggunakan beberapa jenis kata, seperti kata kerja dan kata benda, karena kalimat lengkap paling tidak terdiri dari subjek dan predikat [11].

Sebagai contoh, terdapat sebuah kalimat tanya yaitu "where is Ubaya?". Proses keyword extraction diawali dengan memenggal kalimat tersebut sehingga menjadi "where", "is", "Ubaya", "?". Setelah itu, sistem akan melakukan penghapusan stopword yaitu kata "is" dan “?”. Sistem akan memberikan POS tag untuk setiap kata yang tersisa, sehingga kata "where" memiliki tag adverb (ADV) dan "Ubaya" memiliki tag pronoun (PROPN). Pengambilan kata penting hanya mengambil jenis kata verb, noun, dan pronoun, maka sistem akan mengambil kata "Ubaya" sebagai keyword dari kalimat tanya tersebut. Selain menggunakan metode POS tagging, metode lain yang dapat digunakan untuk melakukan keyword extraction adalah term weighting atau pembobotan term.

\section{Term weighting}

Term weighting atau pembobotan term dilakukan berdasarkan hubungan antara kata dan dokumen serta frekuensi kemunculannya. Metode pembobotan yang digunakan adalah TF-IDF (Term Frequency - Inverse Document Frequency). Term Frequency menghitung jumlah kata yang muncul pada dokumen yang ada. Inverse Document Frequency menganggap istilah yang jarang muncul dalam dokumen lebih penting daripada yang sering muncul. Oleh karena itu, semakin sedikit kata yang muncul dalam dokumen, semakin penting kata tersebut dan semakin tinggi nilai IDF [12]. Pembobotan term dengan TF-IDF dihitung berdasarkan Persamaan 1.

$t f . i d f=t f x i d f$

Di mana tf adalah term frequency, yaitu kemunculan suatu term/token pada dokumen tertentu. Sedangkan idf adalah inverse document frequency, yaitu nilai log basis 10 dari 
jumlah $N$ dokumen dibagi nilai $d f$. Variabel $d f$ adalah frekuensi dokumen yang merupakan jumlah dokumen yang memiliki term tertentu [13]. Oleh karena itu, IDF dapat dihitung berdasarkan Persamaan 2.

$$
i d f=\log \frac{\mathrm{N}}{\mathrm{df}}
$$

\section{E. N-Grams}

$\mathrm{N}$-Grams adalah sebuah metode yang digunakan untuk memecah sebuah kalimat menjadi beberapa bagian, di mana masing-masing bagian terdiri dari $N$ kata. Jumlah $N$ dalam $N$ Gram didasarkan pada jumlah kata yang terkandung dalam kalimat [14]. Ketika jumlah kata dalam kalimat adalah $X$, jumlah maksimum $N$ yang tersedia untuk $N$-Gram adalah $X$, dan jumlah kombinasi yang diperoleh setelah mengeksekusi $\mathrm{N}$-Gram adalah $\mathrm{X}-(\mathrm{N}-\mathrm{l})$. $\mathrm{N}$-Grams yang sering digunakan adalah unigrams $(\mathrm{N}=1)$, bigrams $(\mathrm{N}=2)$, dan trigrams $(\mathrm{N}=3)$. Ilustrasi untuk metode $N$-Grams dapat dilihat pada Gambar 1 di bawah ini.

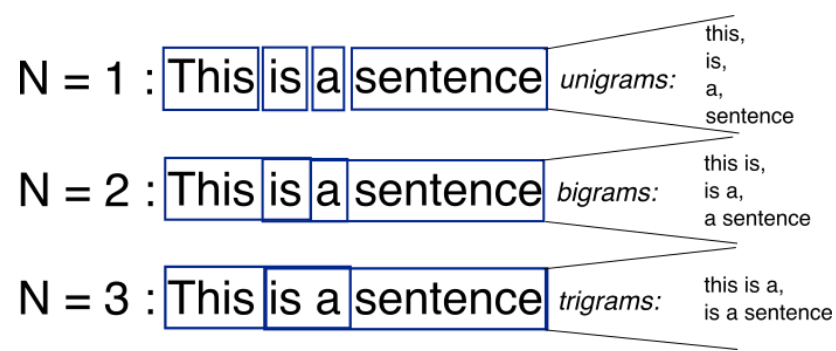

\section{Gambar 1. Ilustrasi Metode N-Grams}

$N$-grams sering dimanfaatkan pada language processing, seperti spelling correction (perbaikan ejaan), word breaking (pemecahan kata), predict upcoming words (prediksi untuk kata selanjutnya), dan text summarization (peringkasan teks). Pada penelitian ini, $\mathrm{N}$-Grams digunakan untuk mendapatkan alternatif jawaban berdasarkan kata kunci.

\section{F. Crawling}

Crawling adalah metode pengambilan data yang umumnya berasal dari suatu halaman web. Program yang mengimplementasikan metode crawling disebut web crawler [15]. Proses crawling diawali dengan mengakses suatu halaman web tertentu, kemudian server akan mengirim respon berdasarkan request yang diberikan. Respon yang diterima akan berisi kode status, tipe konten, character encoding, dan konten web itu sendiri. Setelah itu, crawler akan membaca respon ini dan mengambil konten yang dibutuhkan.

Crawling dapat dimanfaatkan untuk berbagai kebutuhan, seperti penggunaan terkait mesin pencari (search engine) atau pencarian data untuk analisis statistik. Pada penelitian ini, crawling digunakan untuk mencari data atau informasi yang berhubungan dengan program Information Technology.

\section{HASIL DAN PEMBAHASAN}

\section{A. Gambaran Kerja Sistem}

Proses kerja chatbot diawali dengan pengguna menginputkan pertanyaan pada user interface yang disediakan. Sistem akan berusaha mengidentifikasi kata tanya yang terdapat pada pertanyaan yang diinputkan user. Pertanyaan tersebut akan mengalami tokenisasi terlebih dahulu sebelum dilakukan identifikasi kata tanya. Proses tokenisasi dilakukan dengan memanfaatkan library NLTK. Setelah proses tokenisasi, sistem akan melakukan pengecekan pada daftar kata tanya yang sudah disiapkan sebelumnya. Apabila tidak ditemukan kata tanya pada pertanyaan yang diinputkan sebelumnya, maka sistem akan mengirim pesan kepada user bahwa format pertanyaan tidak sesuai, sehingga user dapat memperbaiki pertanyaan yang diinputkan. Sedangkan apabila kata tanya ditemukan, maka sistem akan melanjutkan ke proses berikutnya yaitu keyword extraction.

Proses keyword extraction diawali dengan penghapusan stopword yang terdapat dalam kalimat tanya yang diinputkan oleh pengguna. Proses penghapusan stopword ini juga akan memanfaatkan library NLTK, karena library tersebut sudah menyediakan daftar stopword dalam bahasa Inggris yang siap untuk digunakan. Sistem kemudian akan mencari kata kunci dengan pada kalimat tersebut dengan memanfaatkan library spaCY.

Setelah kata tanya dan kata kunci diperoleh, sistem akan mencari jawaban yang sesuai pada database yang ada. Terdapat 30 kombinasi kata tanya, kata kunci, beserta jawabannya pada database yang telah disediakan, dimana hal tersebut didapatkan dari hasil wawancara dengan Ketua Jurusan Teknik Informatika, Universitas Surabaya dan perwakilan dari Direktorat MPR, Universitas Surabaya. Apabila pencarian jawaban ditemukan pada database, maka sistem akan menampilkan jawaban tersebut kepada user. Sedangkan apabila pencarian jawaban tidak ditemukan, maka sistem akan mencari sinonim dari kata kunci dengan memanfaatkan kamus thesaurus. Setelah itu, sistem akan mengkombinasikan sinonim yang didapatkan dengan kata tanya. Hasil kombinasi-kombinasi tersebut akan digunakan untuk proses pencarian ulang jawaban pada database. Apabila jawaban masih tidak ditemukan, maka sistem akan melakukan crawling ke halaman-halaman web terkait untuk mencari jawaban yang sesuai.

Proses crawling diawali dengan menggunakan kombinasi awal dari kata tanya dan kata kunci hasil keyword extraction. Apabila hasil crawling awal ini tidak memberikan hasil jawaban, maka akan dilakukan lagi proses crawling dengan menggunakan hasil kombinasi-kombinasi sinonim kata kunci dengan kata tanya. Jawaban yang ditemukan berdasarkan hasil crawling akan disimpan ke dalam database, beserta kombinasi kata tanya dan kata kunci yang digunakan. Hal ini dimaksudkan agar ke depannya proses pencarian jawaban menjadi lebih cepat, apabila ada user lain yang menanyakan pertanyaan serupa, karena sistem tidak perlu melakukan proses crawling lagi. Sistem akan memberikan pesan kepada user untuk menanyakan hal lain, apabila setelah proses crawling masih tidak ditemukan jawaban yang cocok. Alur proses kerja 
dari sistem chatbot yang dibangun, dapat dilihat juga pada Gambar 2 berikut.

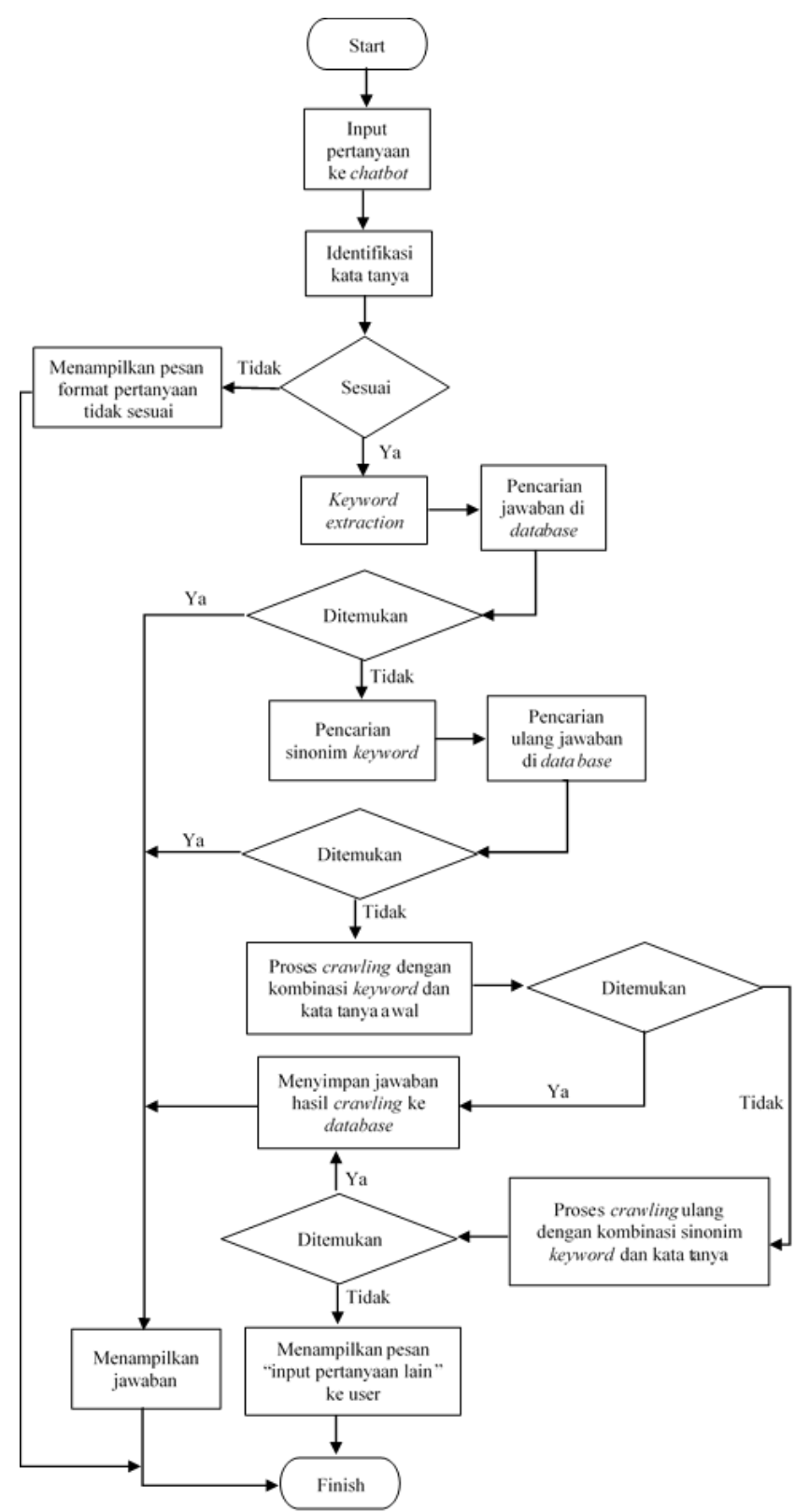

Gambar 2. Flowchart Alur Kerja Sistem Chatbot

\section{B. Uji Coba Sistem}

Pada bagian ini, akan menjelaskan uji coba yang dilakukan pada aplikasi chatbot yang telah dibangun. Chatbot diuji dengan menginputkan tiga jenis pertanyaan yang berbeda yaitu pertanyaan di mana jawaban sudah tersedia di database, pertanyaan di mana jawaban tidak terdapat di database sehingga sistem harus melakukan crawling, dan pertanyaan di mana jawaban tidak ditemukan di database maupun dari hasil crawling. Selain itu, dilakukan juga uji coba pada chatbot apabila diinputkan kalimat pertanyaan dengan format yang salah.
Pertama chatbot diuji dengan menginputkan pertanyaan "what is the accreditation of ITDD?", seperti yang ditunjukkan pada Gambar 3. Pertanyaan tersebut sudah tersedia di database dengan jawaban adalah "A". Chatbot memerlukan waktu selama 6,96 detik untuk mencari dan menampilkan jawaban dari pertanyaan tersebut.

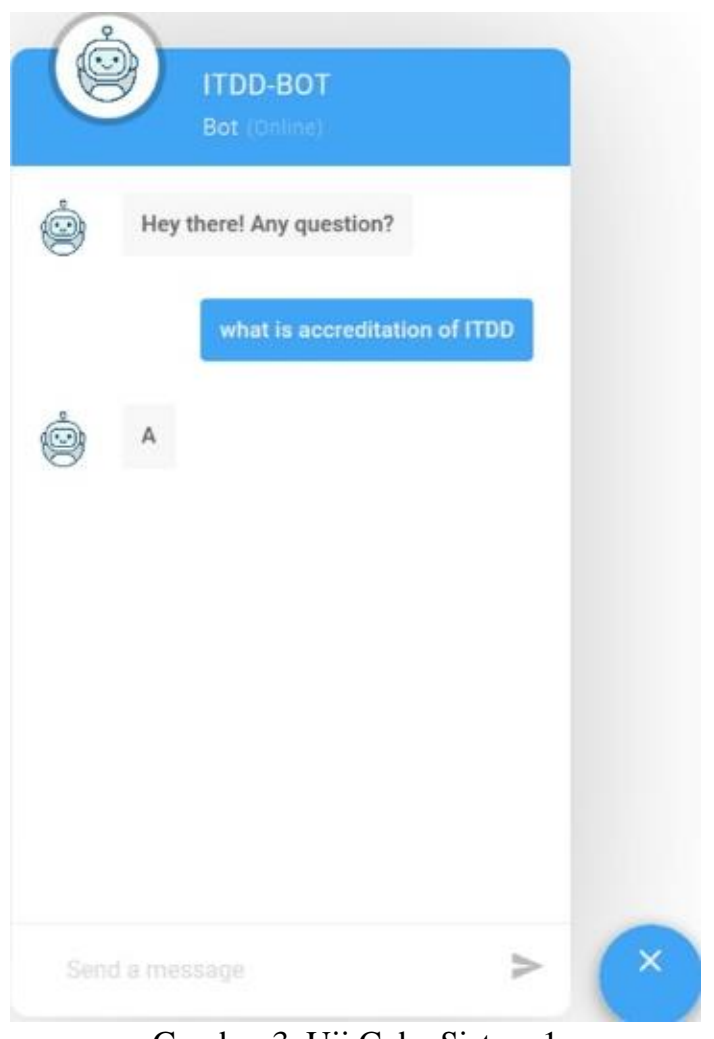

Gambar 3. Uji Coba Sistem 1

Uji coba kedua dilakukan dengan menginputkan pertanyaan yaitu "What is $Q U T$ ", di mana pertanyaan dan jawaban tidak terdapat di database, sehingga sistem akan melakukan crawling untuk mencari jawaban yang sesuai. Sistem melakukan crawling pada halaman web dari Queensland University of Technology (QUT) seperti yang diperlihatkan pada Gambar 4. Proses crawling ini menyebabkan pencarian jawaban memerlukan waktu yang lebih lama dari sebelumnya, yaitu 10,68 detik. Hasil pencarian jawaban ditampilkan ke user seperti yang ditunjukkan pada Gambar 5.

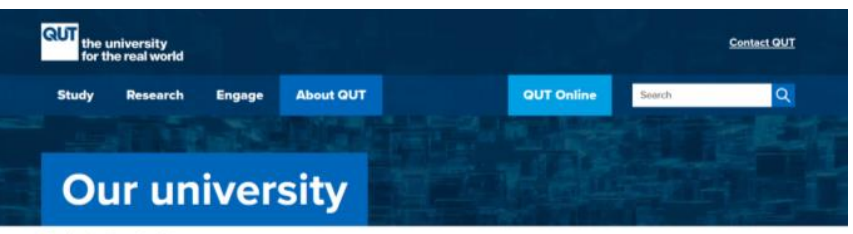

A About Our university

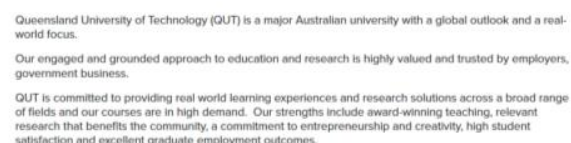

Gambar 4. Halaman Web QUT 


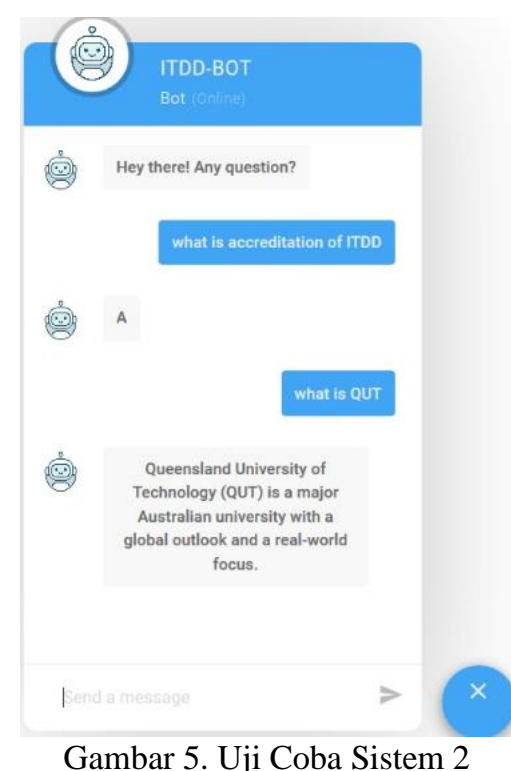

Pada percobaan ketiga, chatbot diberikan pertanyaan yaitu "How many students enrolled in ITDD", di mana pertanyaan dan jawaban yang terkait tidak tersedia di database maupun dari hasil crawling. Untuk percobaan ketiga ini, chatbot akan menampilkan pesan bahwa chatbot masih dalam proses pengembangan, seperti yang dapat dilihat pada Gambar 6 . Proses pencarian jawaban membutuhkan waktu yang cukup lama yaitu 83,12 detik. Hal ini dikarenakan sistem mencoba untuk mencari jawaban yang sesuai dari berbagai macam sumber yang ada. Jawaban dari pertanyaan tersebut sebenarnya dapat diperoleh pada Sistem Akademik Universitas Surabaya. Akan tetapi, dikarenakan sistem akademik tersebut berisi data-data yang penting dan rahasia, maka chatbot tidak diperkenankan untuk melakukan crawling data di dalamnya.

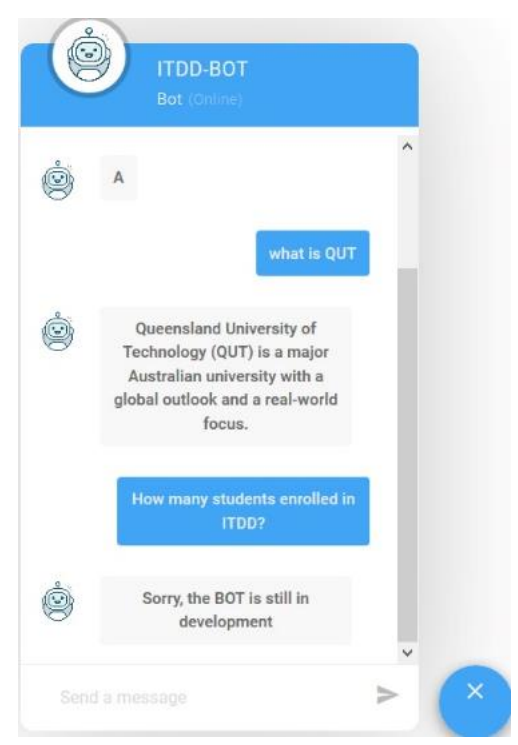

Gambar 6. Uji Coba Sistem 3

Uji coba terakhir dilakukan dengan menginputkan pertanyaan dengan format yang salah, yaitu "this is bot for
ITDD?". Sistem tidak mengganggap kalimat tersebut sebagai pertanyaan yang valid karena tidak mengandung kata tanya seperti what, who, where, when, why, dan how. Oleh karena itu, chatbot akan memberikan pesan ke pengguna untuk menginputkan pertanyaan dengan format yang sesuai, seperti yang ditunjukkan pada Gambar 7. Proses ini berlangsung relatif cepat yaitu 5,45 detik karena sistem tidak melakukan proses pencarian jawaban, baik pencarian di database maupun dengan proses crawling.

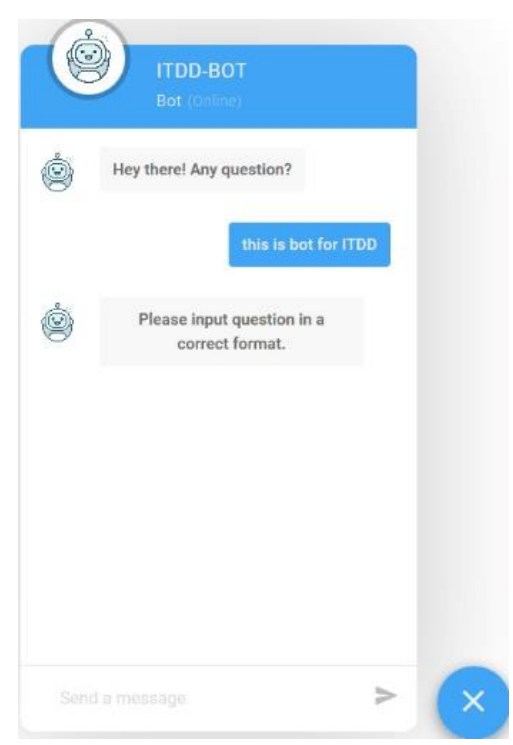

Gambar 7. Uji Coba Sistem 4

\section{User Validation}

User validation adalah salah satu metode validasi, di mana user akan mencoba langsung sistem yang telah dibangun dan kemudian menilai apakah output yang diberikan oleh sistem sudah sesuai dengan kebutuhan user. Pada penelitian ini, validasi dilakukan oleh 10 user, di mana setiap user akan menginputkan 5 pertanyaan untuk menguji chatbot yang telah dibuat. Gambar 8 menunjukkan bahwa akurasi dari sistem chatbot yang dibangun yaitu $76 \%$, berdasarkan user validation yang dilakukan. Akurasi sistem dihitung dengan cara, jumlah validasi benar dibagi total pertanyaan dan dikali $100 \%$, sehingga akurasi $=(38 / 50) \times 100 \%=76 \%$.

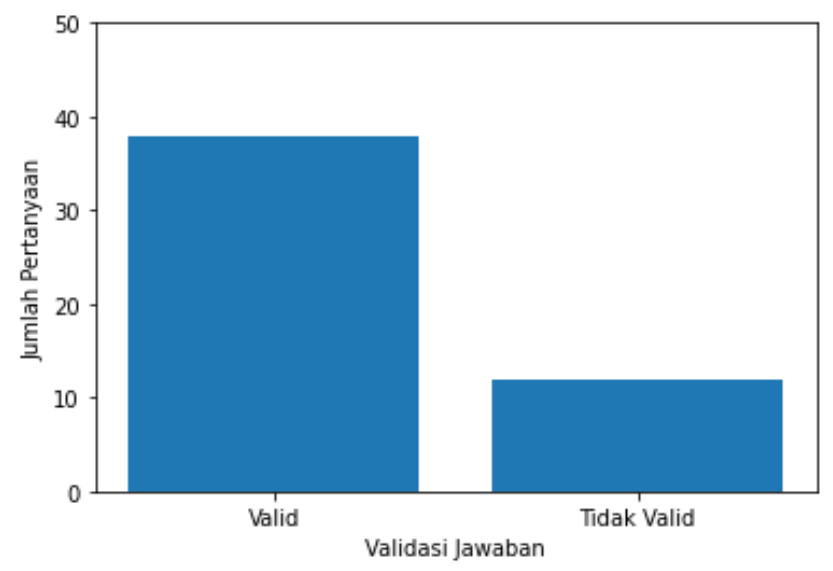

Gambar 8. Hasil User Validation 
Berdasarkan hasil user validation yang dilakukan, masih ditemukan 12 pertanyaan yang menghasilkan jawaban yang tidak sesuai dengan kebutuhan user. Hal ini disebabkan oleh keterbatasan sumber data yang dimiliki, baik yang ada di database, maupun sumber-sumber lain saat sistem melakukan crawling. Pada hasil user validation, masih ditemukan juga pertanyaan-pertanyaan yang memiliki makna sama, tetapi jawaban yang dihasilkan berbeda, sehingga hasil validasi menjadi tidak sesuai. Sebagai contoh, pertanyaan "Who is the head of ITDD program?" dan "Who is the head department of ITDD?". Pada pertanyaan pertama, sistem memberikan output jawaban "Religion Ethics English", sedangkan untuk pertanyaan kedua menghasilkan jawaban "Budi Hartanto".

Pada dua pertanyaan tersebut, hanya pertanyaan kedua yang menghasilkan jawaban yang sesuai. Hal ini dikarenakan ada kata kunci yang dihasilkan berbeda. Pertanyaan pertama menghasilkan kata kunci "head", "ITDD", dan "program", sedangkan pertanyaan kedua menghasilkan kata kunci "head", "department", dan "ITDD". Perbedaan tersebut terletak pada kata kunci "program" dan "department", di mana berdasarkan kamus thesaurus yang digunakan pada sistem, kedua kata tersebut tidak saling bersinonim satu sama lain.

Selain alasan yang disampaikan di atas, beberapa pertanyaan masih menghasilkan jawaban yang tidak sesuai, karena kombinasi kata kunci yang dihasilkan dari suatu pertanyaan sangat banyak dan beragam. Seperti yang sudah dijelaskan pada sub bab III.A, apabila pencarian jawaban tidak ditemukan dengan kata kunci awal, maka sistem akan mencari sinonim kata kunci tersebut dan melakukan pencarian ulang. Sebagai contoh terdapat pertanyaan berikut, "Where will we live when we're abroad". Pertanyaan tersebut menghasilkan kata kunci "live" dan "abroad". Kata "live" mempunyai 20 sinonim, sedangkan "abroad" memiliki 3 sinonim, dan apabila sinonim-sinonim tersebut dikombinasikan, maka akan ada 60 kombinasi kata kunci yang bisa digunakan untuk pencarian ulang jawaban. Hal ini menyebabkan kombinasi jawaban yang didapatkan menjadi beragam dan tidak sesuai dengan yang diinginkan oleh user.

Penyebab lainnya sehingga hasil user validation tidak optimal yaitu ada pertanyaan yang sebenarnya sudah memberikan jawaban yang benar, tetapi tidak sesuai dengan kebutuhan user. Hal ini dapat dilihat pada pertanyaan berikut "How to apply ITDD", di mana jawaban dari pertanyaan tersebut adalah "http://daftar.ubaya.ac.id. Click on this link for more information". Pada kasus tersebut, user menginginkan agar semua informasi-informasi yang terdapat pada link http://daftar.ubaya.ac.id juga ditampilkan di chatbot, sehingga user tidak perlu lagi untuk melakukan scanning dan skimming pada link tersebut untuk memperoleh informasi yang lengkap.

\section{Cross Validation}

Cross Validation adalah metode validasi yang mengambil sebagian dataset untuk dijadikan sebagai data testing. Validasi dilakukan dengan cara membandingkan, apakah hasil klasifikasi atau prediksi yang dilakukan sistem sudah sesuai dengan data asli klasifikasi atau tidak [16]. Akurasi sistem dapat dihitung dengan cara, jumlah validasi benar dibagi dengan total data testing, kemudian dikalikan dengan $100 \%$.

Pada penelitian ini, data testing didapatkan dengan mengambil $20 \%$ data dari total 30 data pertanyaan dan jawaban yang ada di database sistem. Pengambilan data testing dilakukan secara acak, dan kemudian data tersebut dihapus dari database sistem. Setelah itu, pertanyaan-pertanyaan pada data testing akan ditanyakan kembali pada sistem chatbot. Hasil cross validation dari sistem chatbot yang dibangun, dapat dilihat pada Gambar 9. Akurasi sistem chatbot yang didapatkan berdasarkan hasil cross validation adalah $83,33 \%$.

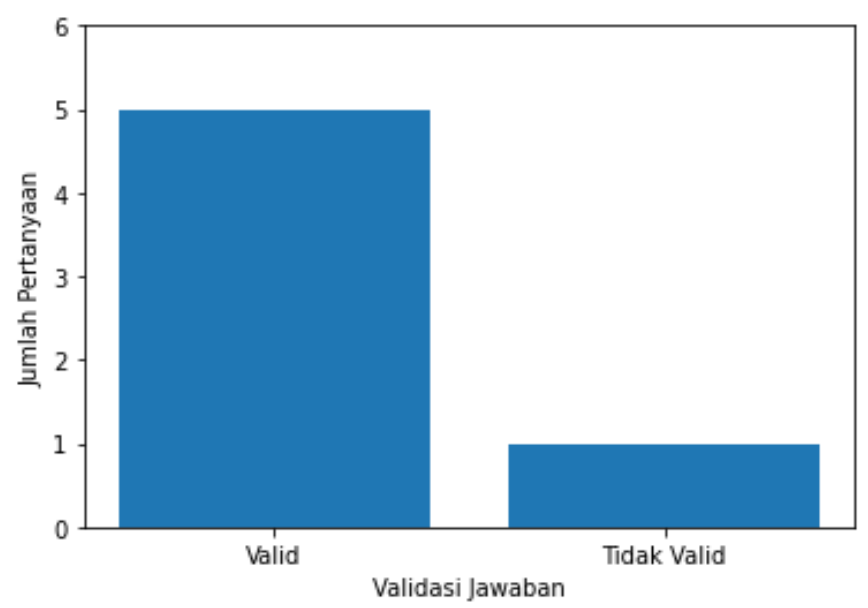

Gambar 9. Hasil Cross Validation

\section{KESIMPULAN}

Berdasarkan hasil user validation dan cross validation yang telah dilakukan, maka dapat disimpulkan bahwa metode NLPdapat diimplementasikan untuk membangun chatbot Program Information Technology, Universitas Surabaya. Akurasi yang didapatkan berdasarkan hasil dua validasi tersebut adalah lebih dari $75 \%$, yang artinya metode NLP cukup baik untuk diterapkan pada penelitian ini. Akan tetapi, chatbot masih perlu dikembangkan lagi agar akurasi menjadi yang lebih baik. Hal ini dapat dilihat dengan masih ditemukannya beberapa kasus yang membuat hasil validasi kurang tepat, seperti yang sudah dijelaskan pada sub bab sebelumnya.

Untuk pengembangan chatbot berikutnya, diharapkan pemrosesan sinonim dari kata kunci dapat berjalan lebih baik lagi, sehingga pencarian jawaban juga dapat berlangsung lebih cepat. Selain itu berdasarkan saran dari user, perlu ditambahkan menu atau halaman admin khusus agar bisa menambahkan daftar pertanyaan, kata kunci, dan jawaban dengan lebih mudah, terutama untuk pertanyaan yang tidak ditemukan jawabannya, sehingga dataset yang ada menjadi lebih kaya dan beragam. Chatbot juga diharapkan untuk dikembangkan agar dapat menerima pertanyaan dalam bahasa Indonesia. 


\section{REFERENSI}

[1] Hakim, M.A \& Nurhayati, S. (2019). Pembangunan Aplikasi Chatbot Midwify sebagai Media Pendukung Pembelajaran Ilmu Kebidanan Berbasis Android di Stikes Bhakti Kencana Bandung. Komputika: Jurnal Sistem Komputer, Vol. 8(1), pp. 45-52.

[2] Wangsanegara, N.K. \& Subaeki, B. (2015). Implementasi Natural Language Processing Dalam Pengukuran Ketepatan Ejaan Yang Disempurnakan (EYD) Pada Abstrak Skripsi Menggunakan Algoritma Fuzzy Logic. Jurnal Teknik Informatika, Vol. 8(2), pp. 1-6.

[3] Suryani, D. \& Amalia, E.L. (2017). Aplikasi Chatbot Objek Wisata Jawa Timur Berbasis AIML. SMARTICS Journal, Vol. 3(2), pp. 47-54.

[4] Benedictus, R.R., Wowor, H. \& Sambul, A. (2017). Rancang Bangun Chatbot Helpdesk untuk Sistem Informasi Terpadu Universitas Sam Ratulangi. EJournal Teknik Informatika, Vol. 11(1).

[5] Dwi, A.R., Imamah, F., Andre, Y.M.S. \& Ardiansyah. (2018). Aplikasi Chatbot (MILKI BOT) Yang Terintegrasi Dengan Web CMS Untuk Customer Service Pada UKM MINSU. Jurnal Cendikia, Vol. XVI, pp. 100-106.

[6] Amalia, E.L. \& Wibowo, D.W. (2019). Rancang Bangun Chatbot Untuk Meningkatkan Performa Bisnis, Jurnal Ilmiah Teknologi Informasi Asia, Vol. 13(2), pp. 137142.

[7] Yuniar, E. \& Purnomo, H. (2019). Implementasi Chatbot "ALITTA" Asisten Virtual Dari BALITTAS Sebagai Pusat Informasi Di BALITTAS. Jurnal Ilmiah Teknik Informatika, Vol. 12(1), pp. 24-35.

[8] Khanna, A., Pandey, B., Vashishta, K., Kalia, K., Pradeepkumar, B., \& Das, T. (2015). A Study of Today's A.I. through Chatbots and Rediscovery of Machine
Intelligence. International Journal of $u$ - and e-Service, Science and Technology, Vol. 8(7), pp. 277-284.

[9] Lisangan, E.A. (2013). Natural Language Processing Dalam Memproses Informasi Akademik Mahasiswa Universitas Atma Jaya Makassar. Jurnal TEMATIKA, Vol. 1(1), pp. 1-9.

[10] Redd, M.V. \& Hanumanthappa. (2014). Semantical and Syntactical Analysis of NLP. International Journal of Computer Science and Information Technologies, Vol. 5(3), pp. 3236-3238.

[11] Siddiqi, S. \& Sharan, A. (2015). Keyword and Keyphrase Extraction Techniques: A Literature Review, International Journal of Computer Applications, Vol. 109(2), pp. 18-23.

[12] Qaiser, S. \& Ali, R. (2018). Text Mining: Use of TF-IDF to Examine the Relevance of Words to Documents. International Journal of Computer Applications, Vol. 181(1), pp. 25-29.

[13] Christian, H., Agus, M.P. \& Suhartono, D. (2016). Single Document Automatic Text Summarization Using Term Frequency-inverse Document Frequency (TFIDF). ComTech: Computer, Mathematics and Engineering Applications, Vol. 7(4), pp. 285-294.

[14] Khan, N.H., Saha, G.C., Sarker, B. \& Rahman, M.H. (2014). Checking the Correctness of Bangla Words using N-Gram. International Journal of Computer Applications, Vol. 89(11).

[15] Prasetyo, V.R. (2018). Searching Cheapest Product On Three Different E-Commerce Using K-Means Algorithm. Proceeding of International Seminar on Intelligent Technology and Its Application (ISITIA). Bali, Indonesia.

[16] Prasetyo, V.R., Hartanto, B. \& Mulyono, A.A. (2019). Penentuan Pembimbing Tugas Akhir Mahasiswa Jurusan Teknik Informatika Universitas Surabaya Dengan Metode Dice Coefficient. Teknika, Vol. 8(1), pp. 44-51. 